The Power of Language and Labels:

“The Mentally Ill” Versus "Person with Mental Illness"

Darcy Haag Granello

Todd A. Gibbs

Counselor Education

Department of Educational Studies

The Ohio State University

Correspondence concerning this article should be addressed to Darcy Haag Granello, Counselor

Education, The Ohio State University, 448 PAES Building, 305 W. 17th Avenue, Columbus, OH 43210 (e-mail: granello.1@ osu.edu) 


\begin{abstract}
College students $(\mathrm{N}=221)$, adults $(\mathrm{N}=211)$, and professional counselors and counseling students $(\mathrm{N}=269)$ were given a measure of tolerance. Half of each sample was given a version that used the term "the mentally ill," and half was given a version that used "person with mental illness." Individuals receiving the version with "the mentally ill" had lower levels of tolerance. Professional counselors had the largest differences in tolerance based on language.
\end{abstract}

Keywords: Individuals with mental illness; the mentally ill; tolerance, stigma; labeling 


\section{The Power of Language and Labels:}

\section{"The Mentally Ill" Versus "Person with Mental Illness"}

In the 1990s, several major publications in the psychological and educational literature proposed the development and use of person-first' language (e.g., American Psychological Association [APA], 1994; Burris, 1992; Craig, 1992). The movement toward person-first language emerged from concerns that use of labels to refer to individuals had the potential to promote bias, devalue others, and express negative attitudes (Committee on Disability Issues in Psychology, 1992). Person-first language was offered as a mechanism to separate the identity of the individual from any clinical diagnosis, disability, or chronic condition. Guidelines for the proper use of person-first language were developed in the wake of the passage of the Americans with Disabilities Act of 1990, in recognition that the strategy of using labels to define people, which had long been used and was widely accepted, resulted in increased stigma in the medical, legal, and social realms (McCoy \& DeCecco, 2011; Russell, Mammen, Russell, \& Swamidhas, 2005).

In the United States, the general linguistic formulation for person-first language is the use of postmodified nouns (e.g., people with mental illness, person with schizophrenia). In this language structure, the disability-related term follows the term for the individual in a very literal "person first" construction. This linguistic strategy is designed to emphasize that the person should not be defined solely by reference to his or her disability. This approach is distinct from premodified nouns (e.g. the mentally ill, schizophrenic) and has gained international support and increased use following the United Nations (2006) adoption of people-first language in forming the Convention on the Rights of Persons with Disabilities (Harpur, 2012). In an attempt to further define and refine the use of person-first language, the Publication Manual of the 
American Psychological Association states "the overall principles of 'nonhandicapping' language is to maintain the integrity (worth) of all individuals as human beings. Avoid language that objectifies a person by her or his condition...that uses excessive and negative labels...or that can be regarded as a slur. Use people-first language, and do not focus on the individual's disabling or chronic condition" (2010, p. 76). The APA website maintains a list of "problematic" (premodified) and "preferred" (postmodified) phrases to use when discussing or writing about individuals with disabilities, noting for example that "person who has a disability" is preferred over "disabled person" and "individual who had a stroke" is preferred over "stroke victim" (APA, 2013).

The development of person-first language is ideologically grounded in the principle of linguistic relativity (popularly known as the Sapir-Whorf hypothesis), which states that language shapes perceptions of the world and significantly influences cognitive processes (Wolff \& Holmes, 2011). Philosophers from Plato to Kant have argued that language influences thinking, and research with individuals learning a second language has shown that attentional biases can be acquired through the frequent, habitual use of certain words or grammatical structures (Boroditsky, Schmidt, \& Phillips, 2003). In other words, language can become a spotlight that highlights certain attributes or qualities of objects or people, making selective aspects of the world more prominent than others (Wolff \& Holmes, 2011). Thus, the use of person-first language is promoted as an intentional strategy to minimize the spotlight effect of the disability and instead focus on respect, dignity, and sensitivity toward previously stigmatized groups (Halmari, 2011).

Over the last several decades, the recognition that premodified nouns label groups of people as equivalent to their disability resulted in the proliferation of organizational name 
changes to postmodified language. For example, in 2003, “The President's Committee on Mental Retardation" became "The President's Committee for People with Intellectual Disabilities," and more recently, the "National Alliance for the Mentally Ill" became the "National Alliance on Mental Illness" (NAMI, 2013).

However, the importance and appropriateness of person-first language has been a matter of debate among groups who advocate for persons with disabilities, and not all organizations or individuals support its use. For example, the National Federation of the Blind adopted a resolution in 1993 rejecting person-first language as a politically correct euphemism (Jernigan, 2009). The Academic Autistic Spectrum Partnership In Research and Education (AASPIRE; 2013) indicates a preference for the premodified noun "autistic person" as this representation is believed to align more closely with the wishes of the autistic self-advocacy community, who argued that autism cannot (and should not) be separated from the individual.

The stances of groups on both sides of this premodified/postmodified argument have been largely grounded in individual and group experience, rather than empirical research. Thus, there is little that can be said from a research perspective about the effects, if any, of premodified or postmodified nouns on the belief structures of those who use these words. More specifically, there is little empirical evidence to inform the discussion about whether terminology affects stigma or tolerance toward individuals with mental illness. Although the APA manual and many in the mental health professions advocate for person-first language for use with people with mental illness, without empirical evidence it is difficult to know whether changes in language affect changes in attitudes or beliefs. The series of studies described in this manuscript is intended to provide empirical data to help further the discussion and support the use of empirically-based strategies for selecting language. 


\section{The Effects of Labeling on People with Mental Illness}

People with mental illnesses are, as a group, devalued and feared by the rest of society (Martinez, Piff, Mendoz-Denton, \& Hinshaw, 2011). Research demonstrates that Americans have high levels of discomfort with people who have a mental illness, ranking their reactions to persons with mental illnesses as even more uncomfortable than to individuals with severe facial disfigurement (Hinshaw, 2007). Studies on the effects of labeling consistently find that media stories often associate mental illness with danger and violence, resulting in lowered levels of ascribed humanity to the individuals with mental illnesses described in the stories (Sieff, 2003).

Public stigma can have profound effects on individuals who are diagnosed with mental illness. People with mental illnesses face devaluation and rejection from others, and the effects of this stigma have been identified as more profound and isolating than the mental illness itself (Martinez et al., 2011). The stigma associated with a diagnosis of a mental illness can impact help-seeking. In fact, although $28 \%$ of the U.S. adult population have a diagnosable mental condition, only about $8 \%$ of people actually seek treatment, with stigma identified as a major barrier to help-seeking (National Institute of Mental Health, 2013)

The combination of the use of premodified nouns with the already existing high levels of public stigma around mental illness may serve to heighten the negative stereotypes toward this vulnerable group of people. In spite of more than 20 years of discussion and recommendations regarding person-first language for individuals with mental illness, media outlets continue to use premodified nouns in their news coverage, as even the most cursory overview attests. There does not appear to be a political or educational component to the use of premodified nouns. The term "the mentally ill" can be found in media outlets on both sides of the political spectrum, in public broadcasting outlets, in print, online, on the radio, and on television. In other words, the use of 
the term "the mentally ill" is used interchangeably with "people with mental illnesses" in nearly all venues. This is consistent with results of a 2011 study that investigated specific news outlets, as well as a compilation of Google News stories, and found vacillation between premodified nouns and postmodified nouns for all types of disabilities, without any discernible pattern (Halmari, 2011). Within the mental health professions, the terms "people with mental illnesses" and "the mentally ill" are often used interchangeably in professional publication venues, and can be found even in manuscripts that discuss stigma and the negative effects of labeling.

The current series of studies arose from a desire to further understand the impact of the use of premodified versus postmodified nouns and their relationship to tolerance toward people with mental illnesses. Twenty years after the original recommendations for the use of postmodified nouns for describing people with mental illnesses were published in the fourth edition of the Publication Manual of the American Psychological Association (1994), there is clearly no consistent use of this language. Without clear empirical evidence that links these labels to tolerance, it is time to find out whether the use of postmodified nouns is worth defending or whether use of these labels is, in fact, simply a semantic argument with little or no relationship to levels of stigma and tolerance.

In the current series of studies, three samples (college undergraduates, adults in a community sample, and professional counselors or counselors-in-training) were given an instrument to measure attitudes toward persons with mental illness. Participants were randomly given a version of an instrument that used premodified language (e.g., the mentally ill) or postmodified language (e.g., people with mental illnesses). There were no other differences in the instrument or between the two subgroups within each sample. Any differences that emerged on the measure of tolerance between the two subsets within each group, therefore, could be 
attributed only to the use of the language contained within the instrument. In this way, the effects of premodified versus postmodified nouns on tolerance toward people with mental illnesses could be isolated as a variable. Because these studies were exploratory in nature and no previous research measuring the effects of labels on tolerance toward persons with mental illness could be found, there were no apriori hypotheses developed. The research question was:

Is there a significant difference in tolerance toward persons with mental illness between individuals who receive a survey that uses premodified versus postmodified language. This question was investigated for three samples: (a) college undergraduates; (b) adults in a community sample; and (c) counselors or counselors-in-training at a national counseling convention.

\section{Methodology}

\section{Participants}

Sample A. College Undergraduates. A sample of 221 college undergraduate students at a large midwestern university was given the instrument in several large courses for non-majors (e.g., history, education, math). The majority of participants was female $(71 \%$; $\underline{\mathrm{N}}=158)$ and Caucasian (81\%; $\underline{\mathrm{N}}=180)$, with 8\% $(\underline{\mathrm{N}}=18)$ identifying as African American; 5\% $(\underline{\mathrm{N}}=12)$ as mixed race; $2 \%(\underline{\mathrm{N}}=5)$ as Hispanic; $2 \%(\underline{\mathrm{N}}=4)$ as Asian American; and $1 \%(\underline{\mathrm{N}}=2)$ as Native American. Participants were divided among undergraduate ranks (8\% Freshmen; 27\% Sophomores; 27\% Juniors; 38\% Seniors), and had an average age of $21.67(\underline{\mathrm{SD}}=2.93$, range 1835). The sample was randomly divided in half, with 110 completing the premodified version and 111 completing the postmodified survey.

Sample B. Community Participants. A sample of 211 adults was recruited from a community center, located in a large midwestern city. The center, a branch of a large non-profit 
organization, promotes health and wellness for individuals, families, and communities. Although there is a monthly fee associated with membership, financial assistance is available and no one is denied membership based on ability to pay. The majority of participants was female $(60 \% ; \underline{N}=$ 126) and Caucasian (85\%; $\underline{\mathrm{N}}=179)$, with $7 \%(\underline{\mathrm{N}}=14)$ identifying as African American; $5 \%(\underline{\mathrm{N}}$ $=10)$ as Native American; $2 \%(\underline{\mathrm{N}}=3)$ as Hispanic; and <1\% each as Asian American $(\underline{\mathrm{N}}=2)$; Mixed Race $(\underline{\mathrm{N}}=1)$; and Other $(\underline{\mathrm{N}}=2)$. Most participants were married or partnered $(72 \%$; $\underline{\mathrm{N}}=$ $152) ; 17 \%(\underline{\mathrm{N}}=37)$ were single; and $7 \%(\underline{\mathrm{N}}=15)$ were widowed (six participants did not respond to this question). Participants ranged from 21 to 85 years of age, with a mean age of $48.58(\underline{\mathrm{SD}}=17.72)$ years. The sample was randomly divided in half, with 107 completing the premodified version and 104 completing the postmodified survey.

Sample C. Professional Counselors and Counselors-in-Training. A sample of 269 professional counselors and counselors-in-training was recruited for participation at the 2013 American Counseling Association International Conference in Cincinnati, Ohio. Surveys were distributed to participants as they waited in lines or sat at tables in the exposition hall. The majority of participants was female $(76 \% ; \underline{\mathrm{N}}=209)$ and Caucasian $(85 \%$; $\underline{\mathrm{N}}=228)$, with $9 \%(\underline{\mathrm{N}}$ $=23)$ identifying as African American; 3\% $(\underline{\mathrm{N}}=9)$ as Asian American; and fewer than $1 \%$ each as Hispanic $(\underline{\mathrm{N}}=2)$, Native American $(\underline{\mathrm{N}}=2)$, Mixed Race $(\underline{\mathrm{N}}=2)$, or Other $(\underline{\mathrm{N}}=3)$.

Participants ranged in age from 22 to 74 , with a mean age of $37.54(\underline{\mathrm{SD}}=12.91)$. More than half of participants described their primary role as professional school or mental health counselor $(40 \% ; \underline{N}=108)$, counselor educator $(10 \% ; \underline{N}=27)$ or both $(14 \% ; \underline{N}=21)$, and $45 \%(\underline{N}=118)$ stated that they held a professional license as a counselor. More than half of participants also stated that they were currently students in counselor education programs, either as Master's Degree students $(40 \% ; \underline{N}=110)$ or Doctoral students $(14 \% ; \underline{N}=37)$. It is important to note that 
34 of the 37 doctoral students also identified as professional counselors. The sample was randomly divided in half, with 137 completing the premodified version and 132 completing the postmodified survey.

\section{Instrument}

Participants received a single instrument, the Community Attitudes Toward the Mentally Ill (CAMI; Dear \& Taylor, 1979). As surveys were distributed, they were alternated between the premodified and postmodified versions, so half of each sample randomly received each version of the instrument.

Community Attitudes Toward the Mentally Ill. The CAMI (Dear \& Taylor, 1979) is a 40-item self-report instrument scored on a 5 point Likert-type scale. It is intended to measure a person's attitudes toward individuals with diagnosable mental illnesses. Respondents are asked to indicate the degree to which they agree with a particular item, with responses ranging from 1 (strongly disagree) to 5 (strongly agree). Half of the items are reverse-scored to minimize the possibilities of response set bias. All reliability and validity information for the CAMI is based on the original version of the instrument, which used the premodified language (e.g., "the mentally ill") unless otherwise noted.

Participants are asked to respond to questions regarding their beliefs about mental illness and people with mental illnesses based on a statement in the instructions to the instrument that reads, "the mentally ill" [version A] or "people with mental illnesses" [version B] "refers to people needing treatment for mental disorders but who are capable of independent living outside a hospital" (Dear \& Taylor, 1979). There are four separate subscales on the CAMI: Authoritarianism, Benevolence, Community Mental Health Ideology, and Social Restrictiveness. 
Each of the subscales has ten items, and there are no individual items used in more than one subscale.

1. Authoritarianism reflects the view that people with mental illness are "an inferior class requiring coercive handling" (Taylor \& Dear, 1981, p. 226). It includes topics such as the need to hospitalize those with mental illnesses and the importance of custodial care. A sample item on this scale is "The mentally ill need the same kind of control and discipline as a young child" [version A] or "A person with a mental illness needs the same kind of control and discipline as a young child." [version B].

2. Benevolence is described as " a paternalistic, sympathetic view, based on humanistic and religious principles" (Taylor \& Dear, 1981, p. 226). It addresses the belief that society should assume responsibility for those with mental illnesses and that people should be sympathetic and kind and willing to be personally involved (Thornton \& Wahl, 1996). A sample item on this scale is "The mentally ill have for too long been the subject of ridicule" [version A] or "People with mental illnesses have for too long been the subject of ridicule" [version B].

3. Social Restrictiveness was intended to measure "viewing [persons with mental illness] as a threat to society" (Taylor \& Dear, 1981, p. 226). It reflects sentiments involving the dangerousness of people with mental illness and the need to maintain social distance (Thornton \& Wahl, 1996). A sample item on this scale is "The mentally ill should be isolated from the rest of the community" [version A] or "People with mental illnesses should be isolated from the rest of the community" [version B].

4. Community Mental Health Ideology has been conceptualized as traditional (mental hospital) versus non-traditional (community-based) mental health care. It addresses the belief in the therapeutic value of community and the acceptance of deinstitutionalized care (Thornton \& 
Wahl, 1996). A sample item (reverse scored) on this scale is "Having the mentally ill living within residential neighborhoods might be good therapy, but the risks to residents are too great" [version A] or "Have people with mental illnesses living within residential neighborhoods might be good therapy, but the risks to residents are too great" [version B].

The CAMI yields four subscale scores and no total score. The responses are scored in such a way that higher scores indicate greater agreement with the concept for each subscale. Therefore, people with more positive attitudes toward individuals with mental illnesses would be expected to have higher scores on the subscales of Benevolence and Community Mental Health Ideology and lower scores on Authoritarianism and Social Restrictiveness. Subscale scores range from 10 (lowest alignment with the scale concept) to 50 (highest alignment with scale concept).

Alpha coefficients on the subscales of the CAMI ranged from .68 to .88 in original studies and subsequent research (Taylor \& Dear, 1981). In the current series of studies, alpha coefficients ranged from a low of .66 (Benevolence, Sample C) to a high of .87 (Community Mental Health Ideology, Sample B). Research on the predictive validity of the CAMI found very strong correlations between CAMI scales and various measures of responses to mental health facilities and programming (for more information, see Taylor \& Dear, 1981). Content (concurrent) validity has been demonstrated with statistically significant correlations between the Stigma Inventory for Mental Illness and selected relevant items from the CAMI (Karidi, et al., in press). Factor analysis was used by the test authors to assess construct validity. There is evidence of some overlap between the subscales, with interscale correlations ranging from .63 to .77 in previous studies (Taylor \& Dear, 1981). In the current studies, interscale correlations ranged from .49-.70. The original factor analysis revealed that the four factors accounted for 
$42 \%$ of the variance (Taylor \& Dear, 1981). Other research on the construct validity of the instrument found similar results (the four factors accounting for 39\% of the variance), with the authors of the more recent study concluding that "although attitude factors derived from the CAMI are rather imprecise and encompass broad concepts, they have a good degree of stability over time and place" (Wolff, Pathare, Craig, \& Leff, 1996, p. 188). It is important to note that these four factors are not mutually exclusive, and people might hold a conflicting range of attitudes (e.g., benevolent, but also socially restrictive) at any point in time.

To determine whether changing the language of the survey affected its reliability, all three samples were combined, and Cronbach's Alpha was run on each subscale for the premodified and postmodified versions. Differences were small between the two versions on all four subscales, indicating that the change in language did not affect the reliability of the instrument (Authoritarianism: premodified $\alpha=.678$, postmodified $\alpha=.717$; Benevolence: premodified $\alpha=.817$, postmodified $\alpha=.804$; Social Restrictiveness: premodified $\alpha=.700$, postmodified $\alpha=.750$; Community Mental Health Ideology: premodified $\alpha=.851$, postmodified $\alpha=.839)$.

The CAMI has been used extensively to measure tolerance toward persons with mental illness in a variety of contexts, including with college students (e.g., Granello \& Granello, 2000; Granello \& Wheaton, 2001; Hayashi \& May, 2011), with the general population (e.g., Addison \& Thorpe, 2004; Diefenbach \& West, 2007), and with mental health professionals (e.g., Hayes et al., 2004; Smith \& Cashwell, 2011).

\section{Data Analysis}

The goal of this series of studies was to determine if there were significant differences on a measure of tolerance toward persons with mental illnesses between individuals in three distinct 
samples who received the survey with either premodified or postmodified language. One half of each sample randomly received the Community Attitudes Toward the Mentally Ill (CAMI) as originally written, using the term "the mentally ill" throughout the entire survey [version A]. The other half received the CAMI with the terms "person with mental illness" or "people with mental illnesses" (depending on sentence construction and grammar) throughout the entire survey [version B]. There were no other differences on the survey. Minimal demographic information was collected from each sample to ensure basic equivalence between the two halves of each sample.

There was no attempt to measure tolerance by any demographic variable and scores were not compared across samples. Accordingly, there was no attempt to make samples representative of larger populations, as the studies were not intended to make broad statements or generalizations about tolerance within these groups. There are many studies that have investigated tolerance in different populations (e.g., Diefenbach \& West, 2007; Hayes et al., 2004), including the mental health professions (e.g., Lauber, Anthony, Ajdacic-Gross, \& Rossler, 2004; Sadow, Ryder, \&Webster, 2002; Smith \& Cashwell, 2004; Theriot \& Ladato, 2012); that have linked tolerance to different individual demographic variables (e.g., Anglin, Link, \& Phelan, 2006; Currin, Hayslip, \& Temple, 2011; Hinkelman \& Granello, 2003); or that have measured the effects of education or training on tolerance (e.g., Krameddine, DeMarco, Hassel, \& Silverstone, 2013; Linden \& Kavanagh, 2011; Pande, Saini, \& Chaudhury, 2011). In the current series of studies, within sample comparisons were done to determine whether, regardless of overall levels of tolerance within each sample, there were significant effects of premodified or postmodified language on tolerance. 
For each sample, a series of four independent sample t-tests were run, one for each of the four subscales on the CAMI. The grouping variable was premodified/postmodified version of the CAMI. Because four tests were run on each set of data, a Bonferroni Correction was done to minimize the risk of family-wise error rates, and the corrected alpha level was set at .0125 . Cohen's $d$ was used as a measure of effect size (Cohen, 1988).

\section{Results}

\section{Study A: Effects of Language on Tolerance for Undergraduate Students}

Undergraduate students who received the premodified version of the CAMI (using the term "the mentally ill") were statistically significantly more likely to score higher on the subscale of Authoritarianism (25.08 vs. 22.98) than their peers who received the postmodified version of the scale $(\underline{\mathrm{t}}=4.04, \underline{\mathrm{p}}<.0001, d=.543$, observed power $=.98)$. Undergraduate students who received the premodified version of the CAMI also were statistically more likely to score higher on the subscale of Social Restrictiveness (26.90 vs. 25.09) than their peers who received the postmodified version of the scale $(\underline{\mathrm{t}}=3.04, \underline{\mathrm{p}}=.003, d=.416$, observed power $=.86)$. There were no statistically significant differences between students who received the two versions of the instrument on Benevolence $(37.45$ vs. $39.02 ; \underline{\mathrm{t}}=-2.46, \underline{\mathrm{p}}=.014, d=.331$, observed power $=$ .69 ) or Community Mental Health Ideology (35.22 vs. 36.18; $\underline{\mathrm{t}}=-1.34, \underline{\mathrm{p}}=.18, d=.181$, observed power $=.27)$.

\section{Study B: Effects of Language on Tolerance for Adults in a Community Sample}

Adult community members who received the premodified version of the CAMI (using the term "the mentally ill") were statistically significantly more likely to score lower on the subscale of Benevolence (38.00 vs. 39.82) than those who received the postmodified version of the scale $(\underline{\mathrm{t}}=-2.72, \mathrm{p}=.007, d=.373$, observed power $=.77)$. Adults in the community who 
received the premodified version of the CAMI also were statistically more likely to score lower on the subscale of Community Mental Health Ideology (33.77 vs. 35.88) than those who received the postmodified version of the scale $(\underline{\mathrm{t}}=-2.57, \underline{\mathrm{p}}=.011, d=.353$, observed power $=$ .73). There were no statistically significant differences between community members who received the two versions of the instrument on Authoritarianism $(22.93$ vs. 22.00$) ; \underline{t}=1.30, \underline{p}=$ $.195, d=.182$, observed power $=.25)$ or Social Restrictiveness $(25.95$ vs. 25.20$) ; \underline{\mathrm{t}}=1.25, \underline{\mathrm{p}}=$ $.21, d=183$, observed power $=.23)$.

Study C: Effects of Language on Tolerance for Professional Counselors and Counselors-inTraining

Professional counselors and counselors-in-training who received the premodified version of the CAMI (using the term "the mentally ill") were statistically significantly more likely to score higher on the subscale of Authoritarianism (18.72 vs. 17.12) than those who received the postmodified version of the scale $(\underline{\mathrm{t}}=3.50, \underline{\mathrm{p}}=.001, d=.428$, observed power $=.94)$.

Professional counselors and counselors-in-training who received the premodified version of the CAMI also were statistically more likely to score higher on the subscale of Social Restrictiveness (22.30 vs. 19.94) than those who received the postmodified version of the scale $(\underline{t}=4.69, \underline{p}<$ $.0001, d=.578$, observed power $=.99)$. There were no statistically significant differences between professional counselors and counselors-in-training who received the two versions of the instrument on Benevolence (44.13 vs. 44.65); $\underline{\mathrm{t}}=-1,20, \underline{\mathrm{p}}=.23, d=.147$, observed power $=.22$ ) or Community Mental Health Ideology (39.56 vs. 39.86); $\underline{\mathrm{t}}=-0.49, \underline{\mathrm{p}}=.62, d=.061$, observed power $=.08)$.

When this sample was subdivided into two groups (those who had already received a master's degree and identified as professional counselors, $\underline{N}=159$, and those who identified as 
current master's degree students, $\underline{N}=110$ ), the same pattern emerged for three of the four subscales: Social Restrictiveness (statistically significant difference for both students and professionals), Benevolence (no statistically significant difference for either students or professionals), and Community Mental Health Ideology (no statistically significant difference for either students or professionals). However, on the subscale of Authoritarianism, language affected professional counselors and counselors-in-training differently. Professional counselors who received the premodified version (using the term "the mentally ill") were significantly more likely to score higher on Authoritarianism than professional counselors who received the postmodified version $(19.32$ vs. 16.85$),(\underline{\mathrm{t}}=3.97, \underline{\mathrm{p}}<.0001, d=.671$, observed power $=.98)$, but was no statistically significant difference on scores for the subscale of Authoritarianism for master's degree students who received the premodified version than the postmodified version $(17.95$ vs. $17.42 ; \underline{\mathrm{t}}=.809, \underline{\mathrm{p}}=42, d=.141$, observed power $=.12)$.

\section{Discussion}

For the individuals in each of the samples in this series of studies, language and labels had a significant effect on tolerance toward persons with mental illnesses. Regardless of overall levels of tolerance, people in each of these samples who saw the premodified term "the mentally ill" reacted differently than those who saw the postmodified language of "person with mental illness." In all cases, those who encountered the term "the mentally ill" responded with lower levels of tolerance on at least some of the CAMI subscales, even though the definition of the premodified or postmodified term at the top of each survey was the same. It appears that the reaction to the label overrode the standardized definition and resulted in differing levels of tolerance. 
College students who received the premodified version of the instrument scored significantly high on the Authoritarianism subscale, with a medium effect size $(d=.543)$. In other words, the use of the premodified label was associated with more than one half a standard deviation increase in Authoritarian attitudes toward individuals with mental illnesses. College students who received the premodified version of the instrument also scored higher on Social Restrictiveness, with an effect size of nearly one-half a standard deviation $(d=.416)$. Thus, the use of the term "the mentally ill" resulted in a reaction that encouraged more restrictive and authoritarian attitudes.

The same pattern that was found in college students also appears in the professional counselor and counselors-in-training sample. It is interesting to note that, although overall counselors and counseling students had very high levels of tolerance, there were still significant differences based on the version of the instrument. Counselors and counseling students who received the premodified version scored significantly higher on the Authoritarianism subscale, with an effect size of nearly one half a standard deviation $(d=.428)$. Counselors and counseling students who received the premodified version also scored significantly higher on the Social Restrictiveness subscale, with a medium effect size $(d=.578)$, or more than half a standard deviation higher than those who received the postmodified version. What is even more striking is that when professional counselors were examined separately, the same patterns emerged, with even higher effect sizes for Authoritarianism $(d=.671)$. In fact, the differences between the two versions on the Authoritarianism subscale were larger for professional counselors than for any other sample or subscale in this series of studies.

Clearly, when professional counselors encounter the term "the mentally ill," they are far more likely to assume the need for a more authoritarian and restrictive approach than when they 
encounter the term "person with mental illness." What is unclear, however, is the reason for this difference. It may be that professional counselors associate the term "the mentally ill" with individuals who have higher levels of severity and require more direct control, even though the definition used in both the premodified and postmodified versions of the instrument was the same.

Finally, adults in the community sample had significantly lower scores on the Benevolence and Community Mental Health Ideology subscales when they received the premodified version of the instrument. For both subscales, the effect size was small $(d=.375$ and $d=.353$, respectively). Of the three samples, then, adults in the community were the least affected by the use of premodified or postmodified language. Nevertheless, even with the smaller effect size, the differences between the two groups was more than one-third of a standard deviation.

Previous research has clearly linked mental illness to perceptions of dangerousness, violence, and unpredictability (e.g., Angermeyer \& Matschinger, 2005; Link, Cullen, Frank, \& Wozniak, 1987; Martin, Pescosolido, \& Tuch, 2000; Phelan \& Basow, 2007), and national surveys suggest that about $75 \%$ of the U.S. population views people with mental illness as dangerous (Corrigan, Watson, Warpinski, \& Gracia, 2004). It is unclear whether the label "the mentally ill" contributes to these negative and stigmatizing perceptions. It may be that this connection is more pronounced with the premodified language, and images and beliefs about "the mentally ill" are more extreme or more frightening than images associated with "person with mental illness." Of course, that is exactly the premise behind person-first language - that it highlights the humanity of the individual, rather than the pathology. 
It is difficult to understand why language impacted different subscales within each sample, and why college students and counselors reacted to the term more strongly in ways that control or restrict individuals and people in the community sample reacted more strongly on subscales focus on kindness, public expenditures, and housing. Adults sampled within the community in which they live and work may be more keenly aware of the how individuals with mental illness may impact (or may be perceived to impact) their immediate community. The Community Mental Health Ideology subscale asks questions specifically about community integration of persons with mental illnesses and the placement of residential treatment facilities within local neighborhoods. Perhaps given the immediacy of this potential, adults in the community who encountered the term "the mentally ill" were more likely to have images of danger or violence than those who encountered the person-first language and were less likely to have benevolent or supportive attitudes. Previous research has supported the widespread effects of the NIMBY (Not in My Back Yard) phenomenon, and group homes for psychiatric residents have faced some of the highest levels of opposition of any group considered for community integration (Piat, 2000). More research into this phenomenon could help better clarify the meaning behind these differences in scores.

There are several limitations to the current study. First and foremost, although all subscales for all samples had differences between the two versions of the instrument in the anticipated direction, only two subscales emerged as statistically significant in each of the three samples. The observed power for five of the six tests that yielded non-significant results was less than .50 , and it is possible that with a larger sample size, there would have been a greater ability to find statistical significance. Nevertheless, in five of the six tests that yielded non-significant results, the effect size was less than .2 (as measured by Cohen's $d$ ), suggesting that even with a 
larger sample size, the magnitude of the difference would still be small. It is important to note that several of the subscales had rather low alpha coefficients in some of the samples, which may have impacted power. However, this was not a pattern that emerged universally. For example, although the subscale with the lowest alpha (.66, Benevolence, Sample C) did not yield a statistically significant difference between the pre- and post-modified versions, several other subscales that did not yield significant differences within the samples had relatively high alpha coefficients $(\alpha=.71$, Authoritarianism, Sample B; $\alpha=.75$, Community Mental Health Ideology, Sample C; $\alpha=.83$, Community Mental Health Ideology, Sample A).

A second limitation is the construct validity of the CAMI instrument. Interscale correlations (ranging from .46-.70 in the current study) raise the concern that there is some construct overlap and the subscales do not measure discrete attitudes. In addition, it is important to remember that these samples are not necessarily representative of the populations from which they are drawn and these studies are not intended to compare tolerance across samples nor to make broad generalizations about how specifically tolerance is impacted by language within the larger population. All three samples, for example, were primarily female. Previous research has found mixed results for the effects of gender on tolerance. Some studies have found that females are less restrictive and more benevolent toward persons with mental illness (Leong \& Zacher, 1999) and that males are more authoritarian and more restrictive (Granello \& Wheaton, 2001), while other studies have found no differences in tolerance toward persons with mental illness based on gender (e.g., Granello \& Granello, 2000; Granello \& Pauley, 2000). Hinkelman and Granello (2003) found that it was not biological sex, but rather strict adherence to traditional gender roles by either men or women that lowered tolerance toward persons with mental illness. 
None of these previous studies, however, examined how language and labels may affect men or women differently, and this is an important next step for researchers to better understand.

Similarly, all three samples were primarily Caucasian, and we are not able to make inferences from the data about how language or labels may affect individuals differently based on their race. There are mixed results for research that attempts to understand the role of race in tolerance. Some studies have found more positive attitudes toward persons with mental illness among African Americans than among White or Hispanics (e.g., Kobau, DiIorio, Chapman, \& Delveccio, 2010) while others found Whites had the most positive attitudes (Carpenter-Song, 2010). As with gender, there is clearly much more research to be done to understand whether and how labels and languages affects individuals from different races and ethnicities in different ways.

Finally, although these studies provide strong and convincing initial evidence regarding the effects of person-first language on tolerance, more research could further our understanding of this phenomenon. It would be interesting and important to discover, for example, whether language affects individuals from different races or genders differently, or whether it impacts actual behaviors, or what specific assumptions people make when they see the term "the mentally ill" that may contribute to the decreased levels of tolerance. There is clearly more work to be done to better understand how language affects tolerance.

\section{Implications}

It is tempting to dig into the nuances of understanding why each of the three samples had significant differences emerge of specific subscales, based on premodified or postmodified language. However, that level of analysis is inappropriate and misses the key finding: individuals in developmentally different stages, with differing levels of tolerance toward persons with 
mental illness, and with differing levels of education and experience about mental illness all are affected by labels. No one (at least not in the three samples in these studies) is immune. After more than 20 years of discussion about premodified versus postmodified language when referring to people with mental illnesses, there is evidence that it matters. Labels matter in college textbooks, in the media, and in the journals, textbooks, and newsletters of the counseling profession. Even when definitions prompt the reader to use the terms "the mentally ill" and "person with mental illness" interchangeably, they are not perceived that way. Although these findings are perhaps not a surprise to anyone who understands the power of language, the results of this series of studies provide concrete evidence that the use of person-first language is an issue that requires increased awareness and action.

Advocacy on behalf of persons with mental illness is at the core of the counseling profession. This series of studies is the first to provide direct evidence of the effects of personfirst language on tolerance toward individuals with mental illness, and the consistent findings across a diverse group of individuals sampled is compelling. With the evidence of the immediate and concrete effects of premodified language on tolerance, there is reason for professional counselors, counseling students, and the counseling profession to become advocates for personfirst language, not only within the profession, but within the larger society. Counselors can challenge media stories that use the term "the mentally ill" and educate members of the press with evidence that this term results in lower levels of tolerance. Editors of journals, textbooks, and professional newsletters can work to eliminate the term "the mentally ill" and replace it with the postmodified "person with mental illness." The American Counseling Association could endorse a policy supporting the use of person-first language for persons with mental illness, provide outreach education to the media, government, and other professionals, and encourage 
more research into the effects of premodified versus postmodified language. In short, the counseling profession and professional counselors can use this evidence to help make societal changes that have significant potential to reduce stigma and improve the lives of our clients.

Finally, given that among the three samples studied, the largest effect sizes for differences in tolerance based on language were among professional counselors, it is clear that counselors must continue to challenge their own assumptions and biases and be aware of how language might influence their decision-making when they work with clients. Among professional counselors in the current studies, the label "the mentally ill" resulted in much higher levels of authoritarian approaches. Although other premodified labels were not studied, it is not too difficult to imagine that they might have equally detrimental effects. "Shorthand" labels for clients among professional colleagues (e.g., "I have a Borderline on my caseload" or "Teachers are complaining about this Bipolar kid") are commonplace in many settings, even though many professionals recognize that this language is not "politically correct." This series of studies offers the possibility that the use of this language may be even more problematic than projecting an image of callousness or disregard for our clients to others. It may, in fact, fundamentally alter our ability to provide the appropriate levels of interventions and care that our clients deserve. 


\section{References}

Academic Autistic Spectrum Partnership In Research and Education. (2013). AASPIRE's use of "Person First Language". Retrieved from: http://aaspire.org/?p=about\&c=language

Addison, S. J., \& Thorpe, S. J. (2004). Factors involved in the formation of attitudes towards those who are mentally ill. Social Psychiatry and Psychiatric Epidemiology, 39, (3), 228234.

American Psychological Association. (1994). Publication manual of the American Psychological Association (4th edition). Washington, D.C.: Author.

American Psychological Association. (2010). Publication manual of the American Psychological Association (6th edition). Washington, DC: Author.

American Psychological Association. (2013). Guidelines for nonhandicapping language in APA journals. Retrieved from: http://www.apastyle.org/manual/related/nonhandicappinglanguage.aspx

Angermeyer, M. C., \& Matschinger, H. (2005). Labeling-stereotype-discrimination: An investigation of the stigma process. Social Psychiatry and Psychiatric Epidemiology, 40, $391-395$.

Anglin, D. M., Link, B. G., \& Phelan, J. C. (2006). Racial differences in stigmatizing attitudes toward people with mental illness. Psychiatric Services, 57(6), 857. doi:

\subsection{6/appi.ps.57.6.857}

Boroditsky, L., Schmidt, L. A., \& Phillips. W. (2003). Sex, syntax, and semantics. In D. Gentner \& S. Goldin-Meadow (eds)., Language in Mind: Advances in the Study of Language and Thought (pp. 61-79). Cambridge, MA: MIT Press. 
Burris, R. W. (1992). Manual of style for depicting people with disabilities. [Brochure] Chicago, Ill.: State of Illinois.

Carpenter-Song, E., Chu, E., Drake, R. E., Ritsema, M., Smith, B, \& Alverson, H. (2010). Ethnocultural variations in the experience and meaning of mental illness and treatment: Implications for access and utilization. Transcultural Psychiatry, 47, 224-251.

Cohen, J. Statistical power for the behavioral sciences (2nd ed.). Hillsdale, NJ: Erlbaum.

Craig, C. (1992). Describing persons with disabilities "to a T." Kennedy Center N.E.W.S. 18(3).

Committee on Disability Issues in Psychology. (1992). Guidelines for non-handicapping language in APA journals. Retrieved from: http://www.apastyle.org/manual/related/nonhandicapping-language.aspx

Corrigan, P. W., Watson, A. C., Warpinski, A. C., \& Gracia, G. (2004). Implications of educating the public on mental illness, violence, and stigma. Psychiatric Services, 55(5), 577. doi:10.1176/appi.ps.55.5.577

Currin, J. B., Hayslip, B., \& Temple, J. R. (2011). The relationship between age, gender, historical change, and adults' perceptions of mental health and mental health services. The International Journal of Aging and Human Development, 72(4), 317-341.

Dear, M. J., \& Taylor, S. M. (1979). Community Attitudes Toward the Mentally Ill. Hamilton, Ontario, Canada: McMaster University.

Diefenbach, D. L., \& West, M. D. (2007). Television and attitudes toward mental health issues: Cultivation analysis and the third-person effect. Journal of Community Psychology, $35(2), 181-195$.

Granello, D. H., \& Granello, P. F. (2000). Defining mental illness: The relationship between college students' beliefs about the definition of mental illness and tolerance. Journal of 
College Counseling, 3, 100-112.

Granello, D. H., \& Pauley, P. (2000). Television viewing habits and their relationship to tolerance toward people with mental illness. Journal of Mental Health Counseling, 22(2), $162-175$.

Granello, D. H., \& Wheaton, J. E. (2001). Attitudes toward persons with physical disabilities and mental illnesses. Journal of Applied Rehabilitation Counseling, 32(3), 9-16.

Halmari, H. (2011). Political correctness, euphemism, and language change: The case of 'people first.' Journal of Pragmatics, 43, 828-840. Doi: 10.1016/j.pragma.2010.09.016

Harpur, P. (2012). From disability to ability: changing the phrasing of the debate. Disability \& Society, 27(3), 325-337.

Hayashi, R., \& May, G. E. (2011). The effect of exposure to a professor with a visible disability on students' attitudes toward disabilities. Journal of Social Work in Disability \& Rehabilitation, 10(1), 36-48.

Hayes, S. C., Bissett, R., Roget, N., Padilla, M., Kohlenberg, B. S., Fisher, G,. Masuda, A., Pistorello, J., Rye, A. K., Berry, K., \& Niccolls, R. (2004). The impact of acceptance and commitment training and multicultural training on the stigmatizing attitudes and professional burnout of substance abuse counselors. Behavior Therapy, 35(4), 821-835.

Hinkelman, L., \& Granello, D. H. (2003). Biological sex, adherence to traditional gender roles, and attitudes toward persons with mental illness: An exploratory investigation. Journal of Mental Health Counseling, 25(4), 259-270.

Hinshaw, S. P. (2007). The mark of shame: Stigma of mental illness and an agenda for change. New York: Oxford University Press. 
Jernigan, K. (March 2009). The pitfalls of political correctness: Euphemisms excoriated". Braille Monitor 52 (3).

Karidi, M. V., Vasilopoulou, D., Savvidou, E., Vitoratou, S., Rabavilas, A. D., \& Stafanis, C. N. (in press). Aspects of perceived stigma: The Stigma Inventory for Mental Illness, its development, latent structure, and psychometric properties. Comprehensive Psychiatry.

Kobau, R., DiIorio, C., Chapman, D., \& Delveccio, P. (2010). Attitudes about mental illness and its treatment: Validation of a generic scale for public health surveillance of mental illness associated stigma. Community Mental Health Journal, 46, 164-176.

Krameddine, Y., DeMarco, D., Hassel, R., \& Silverstone, P. H. (2013). A novel training program for police officers that improves interactions with mentally ill individuals and is costeffective. Front Psychiatry,4, 9.

Lauber, C., Anthony, M., Ajdacic-Gross, V., \& Rossler, W. (2004). What about psychiatrists’ attitude to mentally ill people? European Psychiatry, 19(7), 423-427.

Leong, F. T., L., \& Zachar, P. (1999). Gender and opinions about mental illness as predictors of attitudes toward seeking professional psychological help. British Journal of Guidance and Counselling, 27, 123-132.

Linden, M., \& Kavanagh, R. (2011). Attitudes of qualified vs. student mental health nurses towards an individual diagnosed with schizophrenia. Journal of Advanced Nursing, 68(6), 1359-1368.

Link, B. G., Cullen, F. T., Frank, J., \& Wozniak, J. F. (1987). The social rejection of former mental patients: Understanding why labels matter. American Journal of Sociology, 92, $1461-1500$. 
Martinez, A. G., Piff, P. K., Mendoz-Denton, R., \& Hinshaw, S. (2011). The power of a label: Mental illness diagnoses, ascribed humanity, and social rejection. Journal of Social and Clinical Psychology, 30(1), 1-23.

McCoy, V. A., \& DeCecco, P. G. (2011). Person-first language training needed in higher education. Retrieved from http://counselingoutfitters.com/vistas11/Article_05.pdf

Martin, J. K., Pescosolido, B. A., \& Tuch, S. A. (2000). Of fear and loathing: The role of “disturbing behavior," labels, and causal attributions in shaping public attitudes toward people with mental illness. Journal of Health and Social Behavior, 41(2), 208-233.

National Alliance on Mental Illness (2013). About NAMI. Retrieved from: http://www.nami.org/

National Institute of Mental Health. (2013). The numbers count: Mental disorders in America. Retrieved from: www.nimh.nih.gov

Pande, V., Saini, R., Chaudhury, S. (2011). Attitude toward mental illness amongst urban nonpsychiatric health professionals. Industrial Psychiatry Journal, 20(1), 17-20.

Phelan, J. E., \& Basow, S. (2007). College students' attitudes toward mental illness: An examination of the stigma process. Journal of Applied Social Psychology, 37(12), 28772902.

Piat, M. (2000). The NIMBY Phenomenon: Community residents' concerns about housing for deinstitutionalized people. Health and Social Work, 25(2), 127-138.

Russell, S., Mammen, P., Russell, P., \& Swamidhas, S. (2005). Emerging trends in accepting the term intellectual disability in the world of disability literature. Journal of Intellectual Disabilities, 9(3), 187-192. 
Sadow, D., Ryder, M., \& Webster, D. (2002). Is education of health professionals encouraging stigma towards the mentally ill? Journal of Mental Health, 11(6), 657-656.

Sieff, E. M. (2003). Media frames of mental illnesses: The potential impact of negative frames. Journal of Mental Health, 12, 259-269.

Smith, A. L., \& Cashwell, C. S. (2011). Stigma and mental illness: Investigating attitudes of mental health and non-mental-health professionals and trainees. Journal of Humanistic Counseling, 49(2), 189-202.

Taylor, S. M., \& Dear, M. (1981). Scaling community attitudes toward the mentally ill. Schizophrenia Bulletin, 7, 225-240.

Theriot, M. T., \& Lodato, G. A. (2012). Attitudes about mental illness and professional danger among new social work students. Journal of Social Work Education, 48(3), 403-413. doi: 10.5175/JSWE.2012.201000079

Thornton, J. A., \& Wahl, O. F. (1996). Impact of a newspaper article on attitudes toward mental illness. Journal of Community Psychology, 24, 17-25.

United Nations. (2006). Convention on the rights of persons with disabilities. Retrieved from: http://www.un.org/disabilities/convention/conventionfull.shtml

Wolff, P, \& Holmes, K. J. (2011). Linguistic relativity. Wiley Interdisciplinary Reviews: Cognitive Science, 2, 253-265.

Wolff, P., Pathare, S., Craig, T., \& Leff, J. (1996). Community attitudes toward mental illness. British Journal of Psychiatry, 168, 183-190. 